Gut, 1978, 19, 650-654

\title{
Changes in the electrolyte content of leucocytes at different clinical stages of cirrhosis
}

\author{
A. N. AlAM, P. WheEler, S. P. Wilkinson, L. POSTON, C. GOLindano, \\ AND ROGER WILLIAMS \\ From the Liver Unit, King's College Hospital and Medical School, Denmark Hill, London
}

SUMMARY The intracellular sodium, potassium, and water content of isolated leucocytes was estimated in 47 patients with cirrhosis. The values for sodium showed a wide scatter. In patients without ascites the mean value was significantly increased but in those accumulating ascites it was normal, although often reduced in individual subjects. Reduced values were found in patients with hyponatraemia associated with end-stage cirrhosis and diuretic treatment. Changes in leucocyte water content closely followed those in sodium content. Leucocyte potassium content was normal except in patients accumulating ascites in whom it was significantly reduced, indicating whole body depletion, and this could be corrected by administration of spironolactone.

Abnormalities of plasma electrolyte concentrations, particularly hyponatraemia and hypokalaemia, are common in cirrhosis especially when ascites is present. Total body measurements have also been reported to be abnormal, with increases in total exchangeable sodium and water (Birkenfeld et al., 1958; Nagant de Deuxchaisnes et al., 1961 ; Traverso et al., 1966) and reductions in total exchangeable potassium $\left({ }^{42} \mathrm{~K}\right)$ (Birkenfeld et al., 1958; Casey et al., 1965), and total body potassium $\left({ }^{40} \mathrm{~K}\right)$ (Soler et al., 1976). Since a large proportion of the electrolyte content of the body is intracellular, changes can be satisfactorily analysed only when both serum values and intracellular electrolyte content are determined. Afifi et al. (1968) reported an increased erythrocyte sodium content in patients with cirrhosis and ascites, but Strub et al. (1955) found no significant abnormalities in intracellular electrolytes as determined on muscle fibre specimens. No consistent changes in leucocyte sodium, potassium, or water were found by Roberts and Baron (1963) in an unspecified number of patients with 'chronic hepatic failure' all of whom had received diuretics. The same group has more recently reported a significant increase in cell water in 13 patients with ascites (Levin and Baron, 1975). Five severely hyponatraemic patients, however, had normal cell water but reduced sodium and potassium content.

In this paper we report measurements of intracellular electrolytes carried out in a series of 47 patients with cirrhosis with varying degrees of

Received for publication 3 February 1978 hepatocellular decompensation. Leucocytes were chosen since they have several advantages for the study of intracellular electrolytes. Not only are they readily obtainable but they have many features in common with most other tissue cells, being nucleated and metabolically active. Erythrocytes, which have also been extensively used for such studies, have the disadvantage that respiration is entirely anaerobic, there is no nucleus, and the large haemoglobin mass can result in technical inaccuracies of estimates of potassium concentration. Muscle fibres obtained by biopsy have the disadvantage of leakage from cut ends and extracellular fluid contamination.

\section{Methods}

\section{PATIENTS}

The 47 patients comprised 27 with alcoholic cirrhosis, eight with active chronic hepatitis (none of whom was receiving corticosteroids), six with cryptogenic cirrhosis, five with primary biliary cirrhosis, and one in association with ulcerative colitis. In all of them cirrhosis was confirmed histologically by liver biopsy. The patients were subdivided into four groups as follows, this not being influenced by the aetiology of their liver disease.

A. Eleven patients without ascites and with a normal plasma sodium concentration, without previous diuretic treatment and taking a normal diet.

B. Twenty-one patients with evidence of increasing ascites as shown by changes in body weight and abdominal girth, with marked sodium retention (urinary sodium excretion $<10 \mathrm{mmol} /$ day). These 
patients had not received diuretics for at least three weeks before admission and were given a dietary sodium intake of $20-50 \mathrm{mmol} /$ day for five days before investigation. Mean plasma sodium, creatinine, and urea concentrations were within normal limits. Nine of these patients were investigated a second time five to seven days after a natriuresis induced by spironolactone in a dose ranging from 200-600 mg daily. Although a natriuresis occurred no patient developed hyponatraemia.

C. Five patients in whom hyponatraemia had developed during a period of marked negative sodium balance following treatment with spironolactone in all cases (300-600 mg daily) and frusemide (80-160 $\mathrm{mg}$ daily) in four. In each instance the plasma sodium concentration returned to normal when the diuretics were discontinued.

D. Ten patients with end-stage cirrhosis associated with hyponatraemia, renal failure, and coma. All died within the subsequent one to three days, and none of them was receiving diuretics, although ascites was present in all.

Leucocytes were separated from peripheral blood by the method of Baron and Ahmed (1969). This involved dextran sedimentation of erythrocytes from approximately $15 \mathrm{ml}$ of peripheral blood and removal of residual erythrocytes by hypotonic lysis. Leucocytes were then resuspended in a tissue culture medium (Tc 199) and 125I human serum albumin added as an extracellular fluid marker. Viability of the leucocytes was demonstrated at this stage by trypan blue exclusion and phase contrast microscopy in the first 12 patients, and at regular intervals thereafter. Cells were then dried, and treated with $0 \cdot 1 \mathrm{~N}$ $\mathrm{HNO}_{3}$ before the final reading for electrolytes was taken (Baron and Ahmed, 1969). The sodium and potassium concentration of the tissue culture medium had previously been corrected to that of each patient's plasma and its osmolality adjusted with choline chloride.

From 24 normal subjects of both sexes, aged from
19 to 50 years, the range for leucocyte water, expressed as $1 / \mathrm{kg}$ dry weight, was found to be from $2 \cdot 53-2 \cdot 81$, representing the mean of all values \pm 2 standard deviations. Similarly, the normal range for leucocyte sodium content was taken as 70-90 $\mathrm{mmol} / \mathrm{kg}$ dry weight, and that for leucocyte potassium content as $365-405 \mathrm{mmol} / \mathrm{kg}$ dry weight. These values were comparable with those reported by Edmondson et al. (1974).

Statistical comparisons between patient groups and normal subjects were made using Student's $t$ test.

\section{Results}

Of the 11 patients without ascites (group A), seven had raised values for leucocyte sodium content and only two were low. The mean value was $108 \mathrm{mmol} / \mathrm{kg}$ ( \pm SD 49) which is significantly higher than 80 $\mathrm{mmol} / \mathrm{kg}( \pm \mathrm{SD} 5)$ found in the 24 normal subjects (Table, Fig. 1).

A wide scatter of values was also found in group $\mathrm{B}$, those accumulating ascites, but the mean was not significantly different from that of the normal subjects.

In those patients with diuretic-induced hyponatraemia (group C) and in those with hyponatraemia associated with end-stage cirrhosis (group D), the leucocyte sodium content, with three exceptions, was below the normal range. The mean values for both groups were significantly reduced, being 23 $\mathrm{mmol} / \mathrm{kg}$ ( \pm SD 17), and $47 \mathrm{mmol} / \mathrm{kg}$ ( \pm SD 28) respectively (Table).

Values for leucocyte water closely followed those for leucocyte sodium, being reduced in most of the patients in groups $C$ and $D$, and not significantly different from normal in groups $\mathbf{A}$ and $B$ (Table, Fig. 1). The correlation coefficient between the values for intracellular water and intracellular sodium, for the complete series of patients, was $r=+0.587(\mathrm{P}<0.001)$.

The mean leucocyte potassium content was within

Table Leucocyte and plasma electrolytes in four clinical subgroups of patients with cirrhosis

\begin{tabular}{|c|c|c|c|c|c|c|}
\hline \multicolumn{2}{|c|}{ Clinical group } & \multicolumn{3}{|l|}{ Leucocyte } & \multicolumn{2}{|l|}{ Plasma } \\
\hline & & $\begin{array}{l}\text { Sodium } \\
(\mathrm{mmol} / \mathrm{kg})\end{array}$ & $\begin{array}{l}\text { Potassium } \\
(\mathrm{mmol} / \mathrm{kg})\end{array}$ & $\begin{array}{l}\text { Water } \\
(l / k g)\end{array}$ & $\begin{array}{l}\text { Sodium } \\
(\mathrm{mmol} / \mathrm{l})\end{array}$ & $\begin{array}{l}\text { Potassium } \\
(\mathrm{mmol} / \mathrm{l})\end{array}$ \\
\hline $\mathbf{A}$ & No ascites & $\begin{array}{l}108 \pm 15 \\
(P<0.001)\end{array}$ & $\begin{array}{l}394 \pm 10 \\
(P>0 \cdot 20)\end{array}$ & $\begin{array}{l}2.72 \pm 0.07 \\
(P>0.30)\end{array}$ & $135 \pm 2$ & $3.90 \pm 0.23$ \\
\hline $\mathbf{B}$ & Accumulating ascites & $\begin{array}{c}74 \pm 6 \\
(P>0 \cdot 30)\end{array}$ & $\begin{array}{l}350 \pm 9 \\
(P<0.001)\end{array}$ & $\begin{array}{l}2.54 \pm 0.07 \\
(P>0.20)\end{array}$ & $133 \pm 1$ & $4 \cdot 19 \pm 0 \cdot 11$ \\
\hline & Liver failure & $\begin{array}{c}47 \pm 9 \\
(P<0.001)\end{array}$ & $\begin{array}{l}396 \pm 7 \\
(P>0.05)\end{array}$ & $\begin{array}{l}2.43 \pm 0.08 \\
(P<0.001)\end{array}$ & $118 \pm 3$ & $4.01 \pm 0.43$ \\
\hline \multicolumn{2}{|c|}{ Normal subjects } & $80 \pm 1$ & $385 \pm 2$ & $2.67 \pm 0.01$ & & \\
\hline
\end{tabular}

Mean values $\pm 1 \mathrm{SE}$ are shown and the significance of the difference from mean values for 24 normal subjects. 

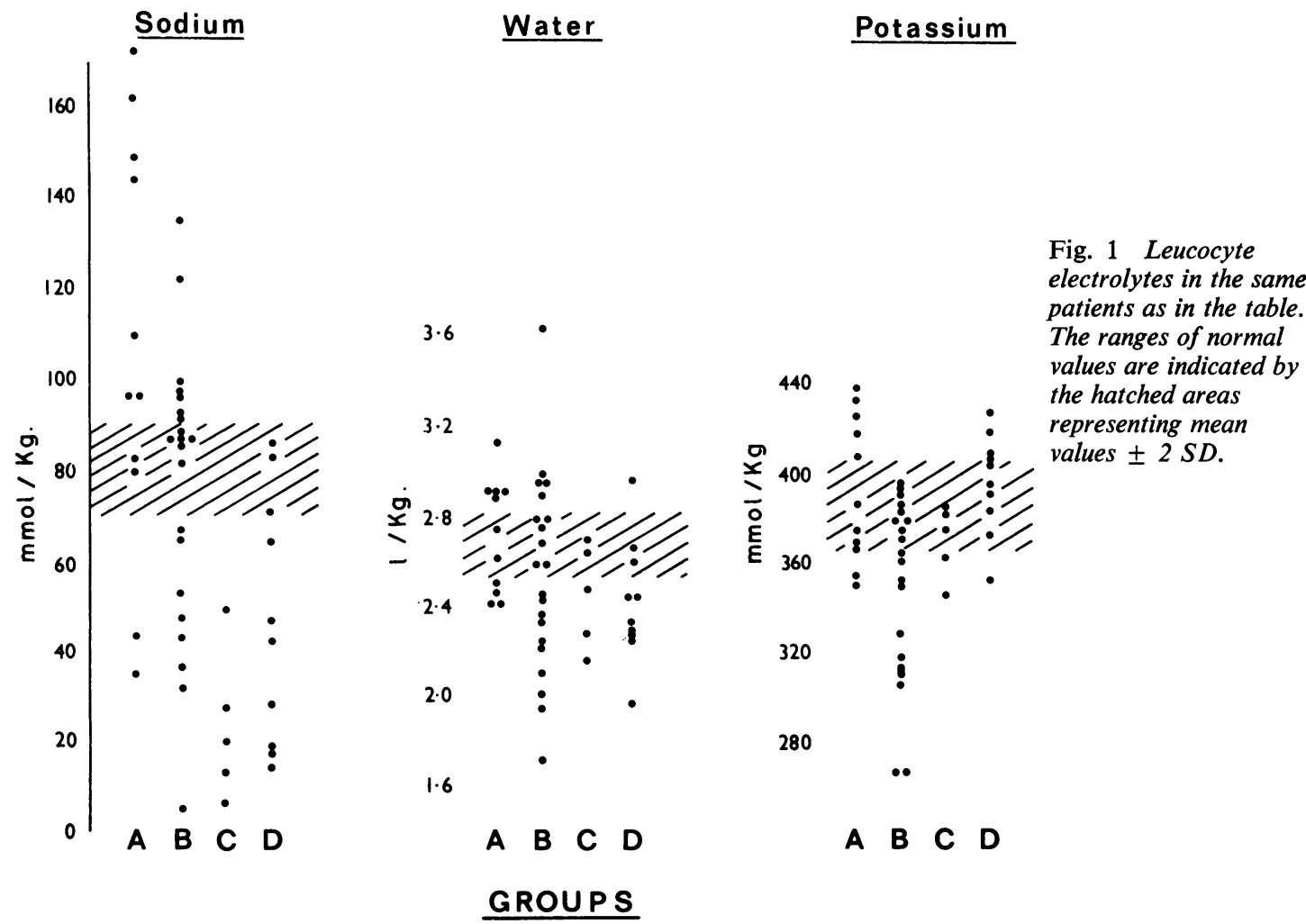

the normal range except in those patients accumulating ascites (group B). Of the 21 patients in this group, 12 had reduced values and the mean for the group $(350 \mathrm{mmol} / \mathrm{kg} \pm \mathrm{SD} 41)$ was significantly reduced compared with the normal subjects (385 $\mathrm{mmol} / \mathrm{kg} \pm$ SD 10) (Table, Fig. 1).

In the nine patients of group B studied before and after induction of a diuresis with spironolactone a significant reduction in the leucocyte sodium content was observed ( $<<0.05$, paired $t$ test) (Fig. 2). The plasma sodium concentration did not change significantly with mean values of $130 \mathrm{mmol} / \mathrm{l} \pm \mathrm{SD} 6$ before and $132 \mathrm{mmol} / 1 \pm$ SD 4 after treatment. Overall there was no significant change in leucocyte potassium content ( $\mathrm{P}>0.05$, paired $t$ test), but, if the five patients in whom this was reduced before treatment are considered separately, there was a significant rise after spironolactone $(P<0.005)$ (Fig. 2). The plasma potassium concentration showed a significant rise after treatment, from $3.7 \mathrm{mmol} / \mathrm{l} \pm$ SD 0.4 to $4.5 \mathrm{mmol} / 1 \pm \operatorname{SD~} 0.6(\mathrm{P}<0.005)$.

\section{Discussion}

The wide variation in leucocyte sodium content was striking. This was particularly surprising in the patients with cirrhosis uncomplicated by ascites

(group A), representing a stage of the disease at which there is no clinical evidence for abnormal sodium metabolism and when the plasma sodium concentration is normal. The present studies throw no light on the mechanisms involved in these changes, but one possibility is that the raised leucocyte sodium content in many of the patients in group $A$ and in a number of those accumulating ascites (group B), is related to whole body magnesium status. Magnesium depletion has been described in cirrhosis both with and without ascites (Lim and Jacob, 1972) and it can also result in a reduced activity of the cell membrane sodium pump (Renn et al., 1967). Furthermore, magnesium deficiency has been shown to be associated with a raised erythrocyte sodium content (Whang and Welt, 1963). However, in many of the patients in group $B$, and in most of those with end-stage cirrhosis (group D), in all of whom sodium retention was the rule, the measured leucocyte sodium content was decreased. This suggests stimulation of the sodium pump which could in turn be due to the action of aldosterone, the plasma concentrations of which are characteristically raised in such patients (Wolff et al., 1966), particularly since it has been demonstrated that aldosterone increases the rate of sodium efflux from various tissues including kidney tubules 


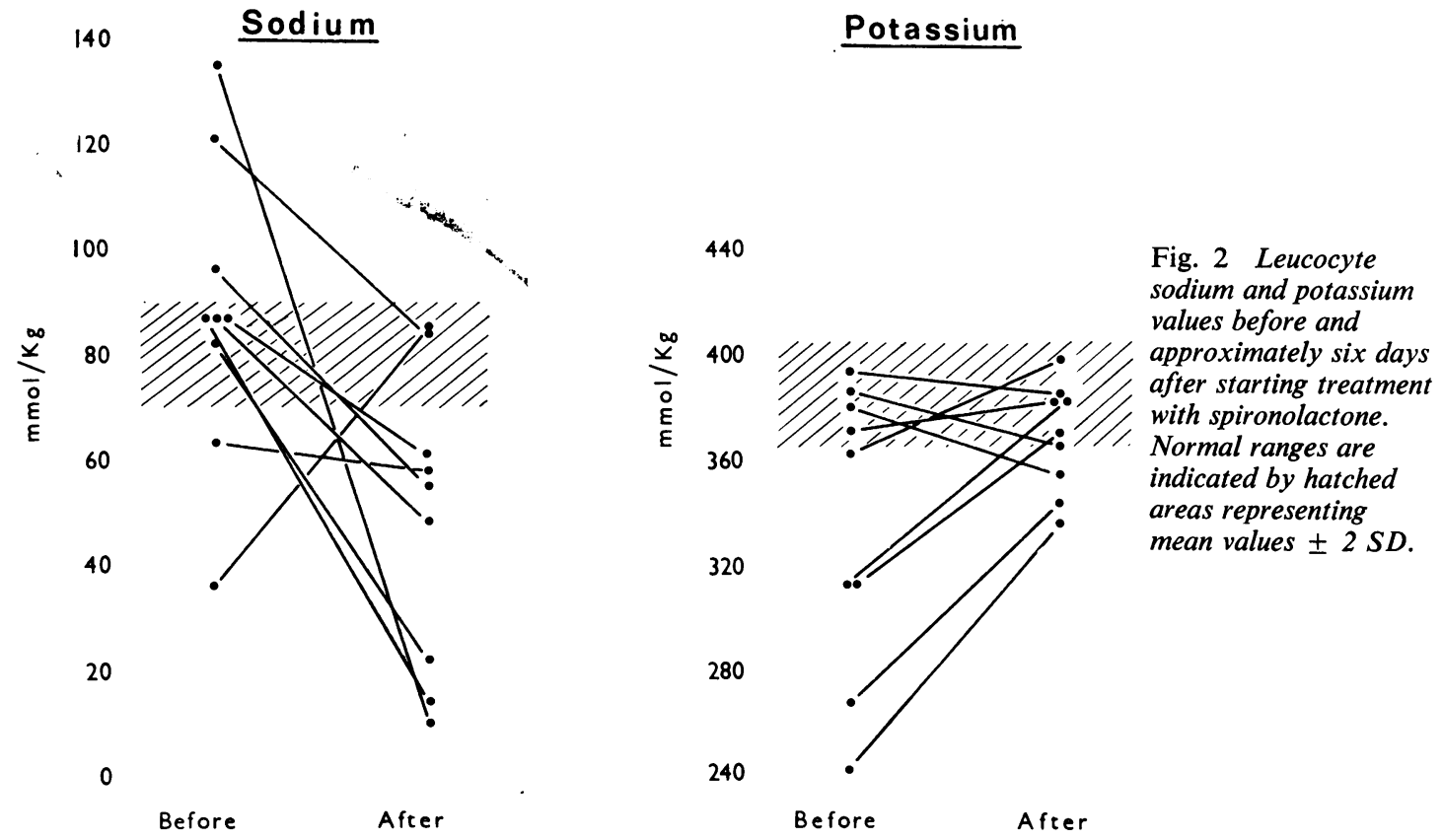

SPIRONOLACTONE

(Schmidt et al., 1975) and barnacle muscle fibres (Bittar and Tallitsch, 1976). Whether aldosterone has a similar effect on leucocytes, however, is not known.

The very low leucocyte sodium content in the patients of group D makes it unlikely that the associated hyponatraemia is a consequence of the passage of sodium into cells, assuming that leucocytes are representative of other body tissues. Even though such patients are recognised as having a high total exchangeable sodium (Traverso et al., 1966), they also have a markedly reduced renal capacity to excrete free water (Shear et al., 1965), and so by inference dilution of the extracellular space is the likely cause of the hyponatraemia. The present findings are in marked contrast to those in patients with fulminant hepatic failure resulting from viral hepatitis, paracetamol overdose, or halothaneassociated hepatitis, in whom we have found hyponatraemia to be associated with high values for the leucocyte sodium content (Alam et al., 1977).

The lowest levels of leucocyte sodium were found in patients with a diuretic-induced hyponatraemia (group C) and as they had been in negative sodium balance, true sodium depletion would seem to have contributed towards this. However, as a result of extracellular fluid volume depletion, the kidneys retain water because of both increased secretion of antidiuretic hormone (Kleeman and Fichman, 1967; Fichman et al., 1971) and also because there is an increased proximal tubular reabsorption of sodium (Earley and Orloff, 1962; Fichman et al., 1971), the latter limiting the amount of sodium available to the ascending limb of the loop of Henle for generation of free water. These factors are likely to contribute to an added dilutional effect in the development of the hyponatraemia. Furthermore, diuretics are potent stimuli to aldosterone secretion, this possibly resulting in an increased sodium efflux from cells.

The possibility raised by some authors (Fichman et al., 1971) that diuretic-induced hyponatraemia may be partly the result of sodium passing into cells in response to associated potassium depletion seems unlikely on the basis of our results.

Values for leucocyte water content followed those for leucocyte sodium and this was taken to represent a tendency towards maintenance of osmotic equilibrium.

The results for leucocyte potassium content are much less variable except for those patients accumulating ascites (group B). Many of these were found to have reduced values and this may also be a secondary effect of hyperaldosteronism resulting in total body potassium depletion. In all of the patients with endstage cirrhosis (group D) renal failure was present, probably resulting in potassium retention and a return to normal of the leucocyte content. Similar findings with respect to total exchangeable potassium 
have been reported (Traverso et al., 1966).

These findings are of clinical relevance. The reduced leucocyte potassium in the patients accumulating ascites substantiates the view of others that potassium depletion is characteristic of this stage of the disease (Casey et al., 1965; Traverso et al., 1966). The use of 'potassium-losing' diuretics such as frusemide and thiazides should therefore be avoided if possible since further potassium depletion may lead to hepatic encephalopathy both by increasing renal ammonia production (Gabuzda and Hall, 1966) and as a result of the induced metabolic alkalosis facilitating uptake of ammonia by brain cells (Warren et al., 1960). The use of spironolactone, a 'potassium-sparing' diuretic, is preferable since it not only directly antagonises the action of aldosterone, but in the present study abnormally low values for leucocyte potassium were corrected following its use. We have recently shown that patients receiving spironolactone alone as maintenance treatment for ascites have a normal whole body potassium (Wheeler et al., 1977). A further reason for avoiding the use of frusemide is that the development of hyponatraemia was invariably associated with its use (group C). Since a spontaneously occurring hyponatraemia in association with end-stage cirrhosis appears to be due to a relative water overload, rigid water restriction is the most logical form of treatment.

Dr A. N. Alam was supported by a grant through the British Council and $\mathrm{Dr} C$. Golindano by C.O.N.I.C.I.T., Venezuela. We are grateful to Linda Rimmer for editorial assistance.

\section{References}

Afifi, F., Boivin, P., and Fauvert, R. (1968). Répartition de l'eau et des électrolytes dans les hématies de sujets normaux et cirrhotiques. Pathologie et Biologie. 16, 847-851.

Alam, A. N., Wilkinson, S. P., Poston, L., Moodie, H., and Williams, R. (1977). Intracellular electrolyte abnormalities in fulminant hepatic failure. Gastroenterology, 72, 914-917.

Baron, D. N., and Ahmed, S. A. (1969). Intracellular concentrations of water and of the principal electrolytes determined by analysis of isolated human leucocytes. Clinical Science, 37, 205-219.

Birkenfeld, L. W., Leibman, J., O'Meara, M. P., and Edelman, I. S. (1958). Total exchangeable sodium, total exchangeable potassium, and total body water in edematous patients with cirrhosis of the liver and congestive heart failure. Journal of Clinical Investigation, 37, 687-698.

Bittar, E. E., and Tallitsch, R. B. (1976). Mode of stimulation by aldosterone on sodium efflux in barnacle muscle fibres. Journal of Physiology, 255, 29-56.

Casey, T. H., Summerskill, W. H. J., and Orvis, A. L. (1965). Body and serum potassium in liver disease. I. Relationship to hepatic function and associated factors. Gastroenterology, 48, 198-207.

Earley, L. E., and Orloff, J. (1962). The mechanism of anti- diuresis associated with the administration of hydrochlorothiazide to patients with vasopressin-resistantdiabetes insipidus. Journal of Clinical Investigation, 41, 1988-1997.

Edmondson, R. P. S., Thomas, R. D., Hilton, P. J., Patrick, J., and Jones, N. F. (1974). Leucocyte electrolytes in cardiac and non-cardiac patients receiving diuretics. Lancet, 1, 12-14.

Fichman, M. P., Vorherr, H., Kleeman, C. R., and Telfer, N. (1971). Diuretic-induced hyponatremia. Annals of Internal Medicine, 75, 853-863.

Gabuzda, G. J., and Hall, P. W., III. (1966). Relation of potassium depletion to renal ammonium metabolism and hepatic coma. Medicine, 45, 481-490.

Kleeman, C. R., and Fichman, M. P. (1967). The clinical physiology of water metabolism. New England Journal of Medicine, 277, 1300-1307.

Levin, G. E., and Baron, D. N. (1975). Leucocyte changes in cirrhosis. Journal of Clinical Pathology, 28, 759.

Lim, P., and Jacob, E. (1972). Magnesium deficiency in liver cirrhosis. Quarterly Journal of Medicine, 41, 291-300.

Nagant de Deuxchaisnes, C., Collet, R. A., Busset, R., and Mach, R. S. (1961). Exchangeable potassium in wasting, amyotrophy, heart-disease, and cirrhosis of the liver. Lancet, 1, 681-687.

Renn, J., Balfe, J. W., Cole, C., and Welt, L. G. (1967). Erythrocyte transport defect in experimental magnesium deficiency (Abstract). Journal of Clinical Investigation, 46, 1107-1108.

Roberts, P. M., and Baron, D. N. (1963). Leucocyte assay as a measure of intracellular water sodium and potassium in chronic hepatic failure and chronic renal failure. Clinical Science, 25, 351-355.

Schmidt, U., Schmid, J., Schmid, H., and Dubach, U. C. (1975). Sodium- and potassium-activated ATPase. A possible target of aldosterone. Journal of Clinical Investigation, 55, 655-660.

Shear, L., Hall, P. W., and Gabuzda, G. J. (1965). Renal failure in patients with cirrhosis of the liver. II. Factors influencing maximal urinary flow rate. American Journal of Medicine, 39, 199-209.

Soler, N. G., Jain, S., James, H., and Paton, A. (1976). Potassium status of patients with cirrhosis. Gut, 17, 152157.

Strub, I. H., Talso, P. J., and Kirsner, J. B. (1955). Intracellular and extracellular fluid and electrolyte alterations in cirrhosis of the liver with edema and ascites. Gastroenterology, 28, 163-175.

Traverso, H. D., Raynaud, C., Blanchon, P., Roberti, A., Vesin, P., Viguie, R., and Kellershohn, C. (1966). Etude des clearances de l'inuline et du PAH, du débit cardiaque, du $\mathrm{Na}$ et du $\mathrm{K}$ échangeables et des liquides extracellulaires, au cours de l'évolution de la cirrhose du foie. Revue Internationale d'Hepatologie, 16, 1377-1398.

Warren, K. S., Iber, F. L., Dölle, W., and Sherlock, S. (1960). Effect of alterations in blood $\mathrm{pH}$ on the distribution of ammonia from blood to cerebrospinal fluid in patients in hepatic coma. Journal of Laboratory and Clinical Medicine, 56, 687-694.

Whang, R., and Welt, L. G. (1963). Observations in experimental magnesium depletion. Journal of Clinical Investigation, 42, 305-313.

Wheeler, P. G., Smith, T., Golindano, C., Alam, A. N., Wilkinson, S. P., Edmonds, C. J., and Williams, R. (1977). Potassium and magnesium depletion in patients with cirrhosis on maintenance diuretic regimes. Gut, 18, 683-687.

Wolff, H. P., Bette, L., Düsterdieck, G., Jahnecke, J., Kobayashi, T., Krück, F., Lommer, D., and Schieffer, H. (1966). Role of aldosterone in edema formation. Annals of the New York Academy of Sciences, 139, 285-294. 